\title{
autêntica
}

ARTIGOS

\section{APRENDENDO A SER PROFESSOR: AS CONTRIBUIÇÕES DO PROGRAMA RESIDÊNCIA PEDAGÓGICA}

\author{
Eliana da Silva Felipe \\ Universidade Federal do Pará (UFPA) \\ Belém, Pará-Brasil \\ licafelipe@hotmail.com \\ ORCID: https://orcid.org/0000-0003-4995-4422 \\ Celi da Costa Silva Bahia \\ Universidade Federal do Pará (UFPA) \\ Belém, Pará-Brasil \\ bpaivabahia@gmail.com \\ ORCID: https://orcid.org/0000-0002-3104-2647
}

RESUMO: $O$ artigo analisa as contribuições do Programa Residência Pedagógica para a aprendizagem profissional da docência de estudantes do curso de Pedagogia da UFPA, problematizando os aspectos mais relevantes à apropriação de saberes profissionais. Para tanto, examina, por meio da análise documental, as diretrizes gerais do Programa, os percursos formativos vivenciados pelos estudantes e documentados em relatórios, anotações e avaliações escritas, entre outros documentos. Aponta-se entre os aspectos mais relevantes à socialização profissional e às aprendizagens dela decorrentes no processo de Residência Pedagógica a qualidade dos espaços formativos, a vivência do trabalho educativo em sua totalidade, o envolvimento pessoal e profissional com as preceptoras, a prática da pesquisa como atividade que articula teoria e prática, produzindo intervenções nos campos de estágio profissional mais criativas e contextualizadas, entre outros aspectos.

PALAVRAS-CHAVE: Residência pedagógica. Formação inicial. Pedagogia. Aprendizagem da docência. 


\title{
LEARNING TO BE A TEACHER: THE CONTRIBUTIONS OF THE PEDAGOGICAL RESIDENCE PROGRAM
}

\begin{abstract}
The paper analyzes the contributions of the Pedagogical Residency Program to the professional learning of teaching students of the Pedagogy Program a Federal University of Pará (UFPA, in northern Brazil), problematizing the most relevant aspects to the appropriation of professional knowledge. To this end, it examines, through documentary analysis, the general guidelines of the Program, the training courses experienced by the students and documented in reports, notes and written evaluations, among other documents. The most relevant aspects identified are the professional socialization and the learning derived from the process of the Pedagogical Residence. Besides that, other aspects include, quality evolved in training spaces; experience of the total educative work; personal and professional involvement with the preceptors; research as an activity that articulates theory and practice. This experience has led to interventions in the field of professional internship that are more creative and contextualized.
\end{abstract}

KEYWORDS: Pedagogicalresidency. Initialformation. Pedagogy. Teachingofteaching.

\section{APRENDIENDO A SER PROFESOR: LAS CONTRIBUCIONES DEL PROGRAMA DE RESIDENCIA PEDAGÓGICA}

RESUMEN: El artículo analizalos aportes del Programa de Residencia Pedagógica al aprendizajeprofesional de losestudiantes de lacarrera de Pedagogía de la UFPA, problematizando los aspectos más relevantes para laapropriación de conocimientosprofesionales. Para tanto, examina, através delanálisis documental, lasdirectricesgeneralesdel Programa, los cursos de formación vividos por losestudiantes y documentados en informes, notas y avaluaciones escritas, entre otros documentos. Entre los aspectos más relevantes de lasocializaciónprofesional e elaprendizaje que deriva delproceso de Residencia Pedagógica, lacalidad de losespacios de formación, la experiencia deltrabajo educativo ensutotalidad, laimplicaciónpersonal y profesionalconlos preceptores, lapráctica de lainvestigación como actividad que articula teoría y práctica, produciendointervecionesenlos campos de lapasantíaprofesional más creativas y contextualizadas, entre otros aspectos.

KEYWORDS: Residencia Pedagógica. Formación inicial. Pedagogía. Aprendizaje de laenseñanza. 


\section{Introdução}

Historicamente, a associação entre docência e instrução esteve na base da constituição do exercício profissional docente. Se no passado formar professores para dominar e transmitir conhecimento respondia às exigências sociais, econômicas e educacionais vigentes, estamos hoje diante de exigências muito mais amplas e complexas.

De uma escola voltada à ilustração da elite à uma escola de massa, diversa e heterogênea em sua configuração sociocultural, e, mais recentemente, ajustada para responder às novas exigências econômicas globais inúmeras tarefas foram incorporadas às suas funções e, consequentemente, às funções da docência, se intensificando as exigências de trabalho e aumentando a responsabilidade dos professores pelos seus resultados.

Problemas advindos das relações sociais estruturalmente desiguais foram transferidos para a esfera da educação, assim como as suas soluções. Nesse contexto, os professores se transformaram na variável controlável das reformas educativas atuais. Sob a lógica liberal, são eles que podem operar a grande mudança social, qual seja, a construção de uma escola inclusiva e cidadã. Essa importância atribuída aos professores transformou a formação inicial e continuada em arena de disputa de projetos ideologicamente distintos.

No bojo desses tensionamentos sociais, programas de iniciação à docência têm sido apontados como alternativa ao incremento da formação inicial, ao aumento da atratividade da carreira docente num contexto de desvalorização profissional e desprofissionalização crescente.

No caso brasileiro, esse incremento à formação inicial, com foco na escola básica,foi efetivado por meio do Edital Capes 06/2018, que definiu os regramentos e as finalidades do Programa Residência Pedagógica, entre elas a que sintetiza seu núcleo de preocupação:

aperfeiçoar a formação dos discentes de cursos de licenciatura, por meiodo desenvolvimento de projetos quefortaleçam o campo da prática e conduzamo licenciando a exercitar de forma ativa a relação entre teoria e prática profissional docente. (BRASIL, 2018a).

Em todo o país foram habilitadas 252 instituições de ensino superior, públicas e privadas, com cotas diferenciadas de bolsas, conforme resultado publicado pelo Ministério da Educação (BRASIL, 2018b).

O Programa Residência Pedagógica na UFPA e Universidade Federal do Pará - UFPA envolveu 11 licenciaturas: Biologia, Química, Matemática, Educação Física, Geografia, História, Língua Portuguesa, Física, Sociologia, Educação do Campo e Pedagogia, totalizando 32 núcleos em dez municípios (Altamira, Acará, Ananindeua, Abaetetuba, Belém, Bragança, Breves, Cametá, Mocajuba e Oeiras do Pará).

O projeto institucional da UFPA contou "com a participação de 1.072 sujeitos sendo 55 docentes orientadores, 96 preceptores, 768 residentes com bolsa e 153 residentes sem bolsa, constituindo-se no maior projeto do Estado do Pará" (UFPA, 2019, p. 2). O núcleo Pedagogia de Residência Pedagógica, em Belém, contou com a participação de 24 residentes, todos com bolsa.

O Programa Residência Pedagógica se inscreve no contexto das políticas neoliberais e repercute sua agenda global no que se refere à formação de professores, ou seja, o esvaziamento de conhecimentos gerais e de 
uma ampla formação cultural, em favor de uma formação assentada, principalmente, no desenvolvimento de competências e habilidades no âmbito didático e metodológico.

No âmbito da política pública o Estado assume o papel de regulador e avaliador dessas políticas. Contudo, a política não paira, absoluta, sobre os indivíduos. Ela opera com dinâmicas interativas e lutas concorrentes, de forma que no contexto das práticas pode ser contestada e modificada.

$\mathrm{Na}$ arena das formulações e dos interesses conflitantes sobre a formação de professores, a socialização profissional dos professores se tornou um tema privilegiado, nas duas últimas décadas, na literatura especializada, pela importância que se passou a atribuir à profissionalização docente, à identidade profissional, aos saberes profissionais da docência, aos complexos processos de integração desses saberes e suas fontes sociais de aquisição, à valorização da atividade profissional como elemento formativo, entre outros temas. Os estudos brasileiros foram amplamente influenciados pelos estudos de Nóvoa (1992, 1999), Tardif (2002) Zeichner (1993) e Tardif e Lessard (1991, 2005).

Otrabalho de compreensão da construção dos saberes profissionais dos professores exige um refinamento analítico da noção de saber. Baseadas em Tardif e Raymond (2000, p. 212), "atribuímos à noção de 'saber' um sentido amplo que engloba os conhecimentos, as competências, as habilidades (ou aptidões) e as atitudes dos docentes" adquiridos em diferentes fontes e em diferentes situações de socialização, pré-profissionais profissionais.

Para Zeichner (2010, p. 483), "essa visão mais ampla sobre os diferentes saberes, que são necessários para formar professores, expande as oportunidades de aprendizagem docente na medida em que novas sinergias são criadas por meio do jogo interativo entre conhecimentos das mais diferentes fontes".

A formação inicial se constitui, nessa abordagem, uma das fontes de aquisição de repertório de conhecimentos próprios à docência, pela socialização profissional que realiza nas instituições de formação, nas escolas de educação básica, entre outros espaços que vão sendo frequentados pelos estudantes no seu percurso de formação. Quanto mais estreita é a relação das instituições de formação com a prática profissional dos professores, nas escolas, mais os estudantes se beneficiam desses processos de socialização.

As reflexões aqui apresentadas buscam compreender as contribuições da Residência Pedagógica na aprendizagem profissional de professores em formação inicial, identificando os saberes profissionais (conhecimentos, habilidades, atitudes, rotinas etc.) de que tomaram posse e as referências identitárias sobre o que significa ser professor que foram se configurando neste processo de tomada de consciência da profissão. Avança, ainda, para as dinâmicas formativas adotadas e para os aspectos que se mostraram mais relevantes e decisivos à aquisição dessas aprendizagens.

\section{Metodologia}

A análise documental, de natureza qualitativa, foi a base da construção deste estudo. Segundo Lüdke e André (1986, p. 38), "a análise documental pode se constituir numa técnica valiosa de abordagem de dados qualitativos seja complementando as informações obtidas por outras técnicas, seja desvelando aspectos novos de um tema ou problema".

A metodologia de análise dos documentos foi a análise de conteúdo, inspirada em Bardin (2011). O corpus documental consistiu em relatórios produzidos pelos residentes, avaliações escritas (de caráter narrativo) realizadas no encerramento do Programa, documentos normativos e regulatórios, entre outros. 
Definido o corpus, realizamos procedimentos exploratórios de identificação de elementos ou temas valorizados nas narrativas dos residentes, comparando-os e buscando apreender relações entre eles. A leitura repetida permitiu a tomada de consciência das similitudes e relações. Os critérios utilizados para a seleção foram o da menção explícita e o da frequência da ocorrência nos textos. Esse trabalho exploratório serviu de base para a definição da problemática levantada. Um referencial teórico prévio foi importante para apoiar essa etapa.

A segunda etapa consistiu na categorização dos elementos ou temas extraídos dos documentos na etapa exploratória. Ainda que as categorias tenham sido definidas a partir do próprio tecido documental, o referencial teórico adotado contribuiu para explicitá-las. Essas categorias foram agrupadas em três marcos interpretativos: saberes profissionais valorizados, identidades ampliadas, afirmadas ou modificadas e processos de organização que aprimoraram a formação para a docência.

Completada essa etapa e tendo em vista a problemática formulada, procedemos à interpretação das suas configurações mais significativas, num processo de ida e de volta, ou seja, da análise à teoria, da teoria à análise, que conjuga referência e inferência, indução e dedução, técnica e imaginação.

\section{Experiências formativas e aprendizagens profissionais da docência}

A docência é compreendida por Tardif e Lessard (2005) como "[...] uma forma particular de trabalho sobre o humano, ou seja, uma atividade em que o trabalhador se dedica ao seu 'objeto' de trabalho, que é justamente um outro ser humano, no modo fundamental da interação humana".

Formar o humano, para um determinado mundo, sob determinados valores ético-sociais, formando-se no processo de formar, define um ethos novo que irrompe a visão de docência como transferência de conhecimentos acumulados.

Sendo a escola o lugar onde se expressam todas as realizações e as contradições da vida social, portanto, do humano, as questões decorrentes de suas funções não são meramente técnico-instrumentais. Elas se inscrevem na ordem da organização do trabalho, das políticas curriculares e de avaliação, na relação da escola com família, na pluralidade social e cultural da infância e da juventude, nos conflitos de valores e de autoridade, para citar algumas delas.

Nessa perspectiva, o plano de trabalho da Residência Pedagógica foi organizado de modo a incorporar essa complexidade e articular diferentes contextos de socialização profissional: a escola, a universidade e outros espaços culturais da cidade como feiras de livro, mercados e museus, que Zeichner (2010) denominou de "espaços híbridos". A centralidade do plano foi a formação acadêmica, profissional e cultural dos residentes.

As escolas-campo que participaram do Programa foram a Creche Municipal Wilson Bahia e a Escola Municipal Amância Pantoja. Essas duas instituições foram escolhidas pelo reconhecimento público do trabalho que realizam e pelas parcerias de formação e pesquisa com o Curso de Pedagogia e com o Programa de Pósgraduação em Educação. Uma dissertação de mestrado intitulada: Escolas de qualidade da rede pública municipal de Educação de Belém/PA segundo IDEB: que qualidade é esta?, analisou 5 escolas com os meIhores desempenhos no Ideb, desde o início da adoção do Índice, entre as quais a Escola Amância Pantoja.

O eixo das ações foi o trabalho pedagógico na sua totalidade, em que a docência não se separa da produção da escola. Com as preceptoras (reconhecidas como formadoras) e com as crianças os residentes puderam 
vivenciar saberes e práticas que são próprios da docência na educação infantil e nos anos iniciais do ensino fundamental: observação e registro, acompanhamento e orientação das crianças em atividades específicas, elaboração de material didático e intervenção pedagógica em áreas do currículo indicadas pelas preceptoras ou escolhidas pelos residentes a partir das observações realizadas. Essas vivências incluíram diferentes espaços (sala de aula, sala de leitura, laboratório de informática, feiras livres, museus, feiras culturais, entre outros) e permitiram, como afirma Nóvoa (2017), firmar posição como professor, afirmar a profissão docente, o que requer conhecimentos específicos e formação para mobilizá-los.

Aprendi maneiras diferenciadas de educar crianças tão pequenas, coisa que eu achava que sabia pelo fato de ser mãe. (Valéria, 2020).

Aprendi que o ensinar do professor é constante e tem que ser diverso [...] Cada aluno é único, mesmo em uma turma com 30, cada um aprende de modo diferente e num tempo específico um determinado assunto lecionado. (Iza, 2020).

Percebo o diálogo entre os alunos e as professoras como o maior, por ser o essencial em sala de aula e este requerer da professora que tenha autoridade e o respeito sem perder o afeto, algo que a maioria das docentes conseguem exercer bem na Amância. (Raissa, 2020).

O verbo aprender, nessas narrativas, deflagra um sentido muito importante na configuração dos saberes necessários à docência. Aliás, um sentido que define todos os outros. Citando Freire (1996, p. 23), "ensinar inexiste sem aprender e vice-versa". Sem disposição pessoal para aprender não pode haver curiosidade, base da criação e recriação da experiência educativa.

Esse conjunto de aprendizagens dizem muito sobre o processo de formar-se, como professor, professora. Preliminarmente, sedistingue o ensinar de tarefas igualmente importantes no trabalho sobre o humano, como aquelas relacionadas à maternidade. O educar, intencional e sistemático, pressupõe conhecimentos que lhes são próprios, que se afirmam e se transformam no tempo histórico. A referência à diversidade e ao diálogo são ilustrativos de valores pedagógicos do nosso tempo. O reconhecimento de que as crianças são diversas e de igual modo sua aprendizagem deflagra a necessidade de formas diferenciadas de intervenção educativa que respeitem suas especificidades, sejam elas sociais, culturais ou cognitivas. Diversidade e diálogo são valores da cultura democrática que foram afirmados na prática de ensinar, diálogo que tem nuances na relação educativa e pressupõe uma mediação complexa entre autoridade e afeto.

No âmbito da gestão e coordenação pedagógica os residentes puderam vivenciar situações próprias da cultura organizacional da escola (encontros escola-família; conselhos de ciclo; plantão pedagógico, projetos de culminância etc.) e aquelas resultantes de determinações externas, como as avaliações de larga escala, mas com incidência nos processos organizativos escolares. Outras oportunidades de aprendizagem, sob a orientação das docentes orientadoras e das coordenadoras pedagógicas das escolas-campo, centraram-se no desenvolvimento de projetos de interesse das escolas, dentre eles: sistematização de resultados de avaliações internas, elaboração de plano pedagógico de apoio para crianças retidas, inventário de material didático disponível na escola e suas possibilidades de uso, além da atualização do PPP, por intermédio de pesquisa com as famílias.

O conhecimento mais amplo sobre a escola na sua singularidade e diversidade contribuiu com a (re) significação de (pré) imagens sobre a escola pública, sobre a atuação de seus profissionais. Uma imagem positiva da escola pública foi forjada neste envolvimento ativo nos diferentes espaços e tempos da escola. 
A residência me permitiu conhecer e compreender a realidade do chão da escola pública e me encantei com o empenho das professoras e a responsabilidade dos envolvidos em fazer educação em ambientes tão adversos. (Iza, 2020).

Não basta estar na escola para conhecê-la e aprender os seus processos de trabalho. Envolver-se ativamente com os profissionais e as diversas situações cotidianas da escola, nos seus diferentes espaços, favorece a identificação pessoal com as suas rotinas, problemas e soluções. No curso da Residência Pedagógica os residentes foram nela penetrando, aprimorando a compreensão das suas contradições, mas também de seus investimentos e conquistas. Por isso é pouco recorrente em suas narrativas, quer nas avaliações, quer nos relatórios, depreciações ao trabalho das escolas, típico de quem olha de fora e de forma apressada, como em outras experiências de estágio onde esse vínculo com o cotidiano da escola não se estabelece.

O tempo investido foi decisivo para a constituição desse vínculo mais estreito com as escolas-campo. Cerca de 200 horas de atividades, excetuando o período de ambientação, foram dedicadas às atividades de docência, gestão e coordenação pedagógica.

O tempo não pode ser considerado uma variável menor quando se trata da integração entre universidade e escola básica nos cursos de formação de professores. O tempo precisa de uma sinergia e ela esteve presente na construção desses percursos de formação: os residentes acolheram a escola e a escola acolheu os residentes, forjando a relação de pertencimento e o sentimento de que lá eram sujeitos daqueles processos, não apenas observadores.

Participar da rotina escolar também trouxe um pertencimento a instituição, já que víamos e participávamos do dia a dia da escola. Assim como também a escola acolheu o projeto, e nos proporcionava a participação nos inserindo nas atividades da escola, não éramos um apenas um observador. (Jakline, 2020).

A sinergia foi importante para que outras aprendizagens pudessem ser vivenciadas, "mais crítica", "mais social", o que não seria possível sem que os estudantes tivessem sido integrados às rotinas da escola e se conectado com a sua história.

O tempo que a gente passa imerso nas escolas também é muito maior, o que fez com que a gente tivesse uma visão também mais crítica, uma visão mais social, uma visão mais próxima da escola e dos alunos do que naquele no contato uma vez por semana do estágio supervisionado, e as crianças acabaram criando vínculo com a gente de tanto que elas estavam próximas. (Valéria, 2020).

Além desta longa imersão nas escolas-campo, cerca de 120 horas foram dedicadas a reuniões de avaliação e planejamento, oficinas de formação e encontros para fins de orientação e acompanhamento. Esses espaços foram especialmente de troca, reflexão, revisitação teórica, orientação pedagógica e, de algumas cobranças, por vezes. A participação em eventos científicos e culturais foi incorporada a esse grupo de atividades. A função de ensinar, como afirma Roldão (2007, p. 101), pressupõe "teorização prévia e posterior", um "agir informado", daí a importância desses espaços de acompanhamento, reflexão e estudo.

Uma ação formativa que busque aprimorar as aprendizagens dos futuros professores requer diversificar espaços e processos, instaurar epistemologias mais dialógicas (entre saberes, entre sujeitos) mas, acima de tudo, requer trazer a profissão, no que ela tem de diverso e complexo, para o centro das preocupações. Citando Nóvoa (2016), "formar um professor é conseguir que alguém aprenda a conhecer, a pensar, a sentir 
e a agir como um profissional docente". É nesse campo que se travam as disputas em torno da identidade ou das identidades docentes, das exigências da prática educativa.

Valemo-nos da metáfora de velejar, utilizada por Freire (1996, p. 22), para pensar como se aprende a ser professor, professora, e os desafios de formá-los.

A prática de velejar coloca a necessidade de saberes fundantes como o do domínio do barco, das partes que o compõem e da função de cada uma delas, como o conhecimento dos ventos, de sua força, de sua direção, os ventos e as velas, a posição das velas, o papel do motor e da combinação entre motor e velas. Na prática de velejar se confirmam, se modificam ou se ampliam esses saberes.

Assim como a prática de velejar, a prática de ensinar "coloca a necessidade de saberes fundantes" de diferentes dimensões: pedagógicos, metodológicos, organizativos, estéticos e ético-políticos. É no encontro e no confronto com a prática de ensinar que esses saberes se ampliam, se confirmam ou se modificam, alterando assim??

\section{Identidade profissional: reconfigurando imagens da escola e da profissão professor}

A identidade profissional do professor é construída a partir da significação social da profissão, que passa por revisões, reafirmações e confrontos: de práticas e teorias, tradição e inovação (PIMENTA, 1999, p. 19).

Assim, em sua dimensão social, a identidade está associada a conhecimentos, competências e práticas necessárias à atividade de ensinar e referenciada por espaços determinados de legitimação que possibilitam a emergência de uma identidade reconhecida, proclamada, atribuída socialmente, por assim dizer, uma identidade para o outro, que define os modos como o outro é ou deve ser identificado.

Contudo, "a identidade não é um atributo fixo para uma pessoa, e sim um fenômeno relacional. [...] acontece no terreno do intersubjetivo e se caracteriza como um processo evolutivo, de interpretação de si mesmo como pessoa dentro de um determinado contexto" (MARCELO, 2009). Há, portanto, uma dimensão da identidade que articula resposta de como o indivíduo se reconhece, se percebe, e não somente como é visto, reconhecido, identificado socialmente.

Essas construções identitárias se referem a saberes profissionais, mas reportam também imagens de si, em interação com imagens da profissão, suas dificuldades, encantos, incertezas.

Quando iniciei o curso de pedagogia eu já sabia que queria atuar como professora e a RP só me fez ter certeza disso. (Patriciane, 2020).

Minha meta sempre foi prosseguir a vida acadêmica e não tinha planos de atuar na educação básica, seja pelo medo de não me adaptar ou até mesmo por me sentir incapaz. Com as vivências na Residência percebi que tenho conhecimento para trabalhar na escola. (Hugo, 2020).

Como se pode observar, o compartilhamento de situações de trabalho profissional, das suas rotinas e dinâmicas próprias afirma percepções e altera outras.

Historicamente, a associação entre professor e transmissão de conhecimento configurou uma percepção de papéis profissionais que privilegia o ensino em situação de sala de aula como função primordial do trabalho 
docente. Mas a diversidade de contextos vividos pelos residentes em situações de trabalho contribuiu para alterar essa percepção culturalmente muito presente em nossos contextos educativos. A ideia de que a escola é um lugar onde acontecem muitas coisas ao mesmo tempo está diretamente relacionada com o fato de que a docência é uma profissão ampla, que as suas funções são múltiplas e realizadas em contextos diversos que incidem uns sobre os outros: sala de aula, escola, sistemas de ensino e comunidade da escolar.

O programa Residência Pedagógica me ofereceu grandes oportunidades de vivenciar experiências, de poder interagir com os alunos, professores e coordenadores, e de ter uma visão do quão complexo é o ambiente escolar e que várias situações acontecem ao mesmo tempo e se deve estar preparado de alguma forma para resolvê-las. (Rodrigo, 2020).

Assim como há situações que acontecem ao mesmo tempo dentro da escola, há situações que acontecem fora dela e que incidem em suas ações. A visão da escola como lugar de conflito, intercruzado com que acontece fora dela altera perspectivas sobre quem são os professores: mediadores da aprendizagem e solucionadores de conflito.

Como residente aprendi que um professor não é um mero transmissor de saber ou que sua aula não é uma preparação para vida futura dos alunos, pois eles já estão vivendo-as. Ser professor é ser mediador da aprendizagem e solucionador de conflitos, estes que muitas vezes são gerados externo à escola, mas eclodem no ambiente escolar. (Iza, 2020).

Compreensão que a docência vai além da sala de aula. As relações familiares interferem na aprendizagem da criança, de forma positiva ou negativa, ter um olhar sensível para entender que as questões que as crianças trazem de casa são percebidas nos comportamentos e desempenho escolar. (Jakline, 2020).

Compreender o que significa ser professor na escola pública, o que significa educar crianças no contexto de uma sociedade marcada por contradições, que se expressam dentro da escola, foi importante para se situar na realidade concreta, mas recusando o fatalismo. Mais que desesperança, o que se alude é a necessidade de sensibilidade para lidar com o que eclode dentro da escola, nos comportamentos e nos desempenhos escolares.

Mas que tipo de socialização profissional permite tomar posse da docência, incorporar saberes fundantes, sentir-se professor, tornar-se professor? Para responder a esta pergunta analisamos aspectos sublinhados, pelos residentes, como positivos e mais decisivos ao sentimento de pertença e ao encorajamento que resultou numa visão mais positiva da profissão. Esses aspectos foram agrupados em dimensões que expressam as opções de formação realizadas, os percursos produzidos e as apropriações que os residentes elaboraram do projeto de formação vivenciado.

\section{Socialização profissional: percursos e apropriações}

Cinco palavras-chave sintetizam a experiência na residência: vivência, pertencimento, possibilidades, diversidade e responsabilidade. (Cintia, 2020).

O exame dos documentos que serviram de fonte para as análises aqui apresentadas permitiu apontar como aspectos mais relevantes e decisivos à aprendizagem profissional da docência no contexto do Programa Residência Pedagógica. Entre esses aspectos elegemos três para apresentar neste artigo. 


\section{Integração escola-universidade e redes de formação e apoio}

As estratégias de integração adotadas possibilitaram a construção de um ambiente favorável à vivência, ao pertencimento e ao senso de responsabilidade recíproca dos residentes com o projeto educativo das escolas-campo, e destas, com o seu processo de formação profissional.

No âmbito das escolas foram realizados planejamentos conjuntos, a cada etapa, com a participação dos residentes, das preceptoras, orientadoras, coordenadoras e gestoras. O planejamento coletivo envolveu decisões compartilhadas e permitiu a realização de ações articuladas com o projeto pedagógico das escolas, o que foi importante ao estabelecimento de uma parceria genuína e a maior integração dos residentes.

O envolvimento pessoal e profissional com os professores/as e com o conjunto de profissionais da escola, a aproximação com a preceptora possibilitou uma aprendizagem direcionada para a necessidade dos alunos, tornando as intervenções mais significativas ao residente, para a preceptora e para os alunos. (Iza, 2000).

As dinâmicas institucionais de escolas e universidades são diferenciadas, o que trouxe dificuldades, em algumas ocasiões. Mas em grande medidaas estratégias adotadas favoreceram, positivamente, o estreitamento das relações institucionais e o alcance de benefícios mútuos. As escolas deram uma significativa atenção aos residentes que, por sua vez, se comprometeram com o seu projeto.

Essa integração resultou em redes de formação e apoio, nas escolas-campo e na universidade, que contribuíram para afirmar valores próprios da docência e fortalecer a imagem de uma atividade profissional que é "interativa e reflexiva" (TARDIF e LESSARD, 2009) e coletivamente construída. Os 24 residentes selecionados para o Programa foram acompanhados, continuamente, por seis preceptoras, duas docentes orientadoras e duas coordenadoras pedagógica. Esse trabalho coordenado se mostrou efetivo no apoio à docência, como se pode observar nesses excertos:

Um ponto que merece atenção é a rede de pessoas que compõem o Programa, assim podíamos contar com uma rede de apoio para facilitar nossa compreensão e nos orientar em nosso fazer pedagógico. (Hugo, 2020).

Um dos pontos mais relevantes da Residência em relação ao estágio supervisionado foram as formações que tivemos na UEI bem como o espaço de socialização das experiências em sala, o que por vezes trouxe orientações e perspectivas diferentes das que vivíamos na escola. (Jakline, 2020).

Nesses diferentes espaços formativos os residentes puderam exercitar, em colaboração com as preceptoras e orientadoras, a reflexividade crítica sobre as práticas, suas tensões, dificuldades e possibilidades. Essas redes acolheram outros interlocutores, professores do curso, na medida em que o planejamento das intervenções foi exigindo atuar nas lacunas de formação ou problematizar referências pedagógicas herdadas de tradições educativas dissonantes com valores educativos assentados aprendizagem ativa e crítica.

\section{Qualidade formativa das escolas-campo}

Uma das referências contemporâneas mais importantes sobre a profissionalização docente é o reconhecimento do espaço de trabalho dos professores como lugar de formação. Seriam todos os espaços de trabalho formativos? O que define um espaço como formativo? 
A ambiência do trabalho é uma condição objetiva à aprendizagem da profissão. Nessa perspectiva, para que a escola se transforme num espaço formativo real para os futuros professores, em que possam refazer identidades pessoais e profissionais, as dinâmicas de trabalho devem favorecer o reconhecimento da educação como uma forma de intervenção no mundo que é intencional, coletiva e planejada, exige tomadas de decisão cujos resultados, positivos ou negativos, possam ser acompanhados e refletidos. Dito de outro modo, onde os professores em formação possam vivenciar dimensões criativas do trabalho de ensinar. Isso pressupõe uma escola que produza a escola, ainda que em ambientes de precariedade, do ponto de vista da organização do trabalho pedagógico e da sua gestão em seus diferentes espaços.

A escola de educação infantil me conquistou [...]. (Valéria, 2020).

A forma como as profissionais trabalham a autonomia de crianças muito pequenas colocando-as como protagonistas de seu desenvolvimento é o diferencial para elas. (Patriciane, 2020).

A escola busca estabelecer relações na tentativa de cuidar da criança além do espaço escolar. (Jakline, 2020).

Destaco o aprendizado acerca das demandas sociais e da comunidade que percebi durante a minha experiência. A importância do diálogo entre a escola, a comunidade e a família. (Cintia, 2000).

A ideia de escola inclusiva que os residentes construíram para si é uma escola integrada com a família e com a comunidade, que ensina cuidando, diversificando (inclusive metodologicamente) e fortalecendo experiências de autonomia.

Essas percepções sobre os problemas e as possibilidades que cercam a realidade da escola pública se deveram, em grande medida, às oportunidades de inserção em espaços coletivos de planejamento, reflexão e avaliação. Por sua vez, a relação de confiança e de cooperação produziram um ambiente favorável à manifestação de opiniões, dúvidas e problemas (pessoais e profissionais), à participação em decisões em que se sentiam aptos e incentivados pelos coletivos das escolas.

Conhecer e intervir em instituições que atuam com públicos tão diversos foi muito importante para a socialização profissional dos residentes. Eles só tiveram a oportunidade de aprender o que é próprio da docência em diferentes etapas da educação básica porque estavam inseridos em espaços que desenvolvem um trabalho considerando as especificidades da educação das crianças e o contexto em que estão inseridas. Portanto, é a possibilidade de encantar, surpreender, sensibilizar e estimular a inventividade, no contexto de múltiplas contradições, que faz do ambiente de trabalho um espaço formativo.

\section{Prática da pesquisa como atividade de articula teoria-prática}

É possível observar que para os residentes o envolvimento com a pesquisa foi um aspecto importante para o aprendizado da docência e para aprendê-la de forma investigativa tanto do ponto de vista acadêmico como do ponto de vista pedagógico.

O programa pode também oportunizar vários estudos de grande relevância para a pesquisa. Essas experiências geraram artigos, relatórios para as disciplinas e até monografias. Foram essas práticas que puderam trazer relatos para a sala de aula na Universidade e colaboraram nas disciplinas, nos debates e seminários, articulando o aporte teórico com as intervenções. (Rodrigo, 2020). 
Nesse processo, registros de campo (obtidos por meio de observações, questionários e conversas) e reflexões da prática educativa nutriram as propostas de intervenção e alimentaram o debate no espaço das salas de aula na Universidade. Este, por sua vez, retroalimentou as experiências desenvolvidas na escola. Trabalhos de conclusão de curso, artigos completos e resumos expandidos foram gerados a partir da Residência Pedagógica.

O excerto abaixo sintetiza o percurso da Residência Pedagógica e os objetivos que ela cumpriu na aprendizagem da profissão docente:

[...] o projeto Residência Pedagógica cumpriu dois significantes objetivos: formar pesquisadores e promover fundamental tempo e espaço para a prática pedagógica de futuros professores. (Luísa, 2020)

\section{Considerações finais}

Este artigo se propôs a comunicar o processo de construção e apropriação de uma experiência de formação docente por meio do Programa Residência Pedagógica. O contexto em que se deu essa construção define, em grande medida, as apropriações que dela resultaram, de forma que possíveis generalizações dependem de aproximações com o campo de ideias e com as condições objetivas e subjetivas que as fizeram florescer.

Feitas essas ressalvas, pode-se afirmar que o programa desenvolvido dá provas cabais que uma formação que valorize o desenvolvimento acadêmico, intelectual e investigativo dos professores em formação não é incompatível com a devida importância que deve ser dada ao trabalho educativo das escolas em suas dimensões pedagógicas e organizativas. Esses saberes são complementares, não concorrentes entre si.

O fortalecimento da escola, em particular da escola pública, não se coaduna com a desintelectualização dos professores.Nesse sentido, a formaçãoacadêmica humanista (que alimenta a democracia e a cidadania) e técnica (que capacita para a sua construção) é insubstituível. Por sua vez, é na ambiência do trabalho que outros diferentes saberes necessários à prática educativa são criados, onde melhor se visualizam os problemas, as tensões, as contradições sociais e as possibilidades de mudança. É lá onde a vida pulsa que nasce a sensibilidade comprometida e engajada, portanto, a responsabilidade ética com a vida, com o direito de aprender, com o dever de ensinar bem os que mais precisam da escola para ampliar sua condição de cidadania.

A Residência Pedagógica pode, pelas práticas concorrentes, articular um projeto de formação que não seja o da simplificação do trabalho de ensinar, mas para isso outras opções teóricas e políticas precisam ser feitas e afirmadas.

\section{REFERÊNCIAS}

BRASIL. Coordenação de Aperfeiçoamento de Pessoal de Nível Superior (Capes). Edital 06/2018.2018a. Disponível em: capes.gov.br/images/stories/download/editais/27032018-Edital-6-Residencia-PedagogicaAlteracao-Il.pdf. Acesso em: 08 ago. 2018.

BRASIL. Coordenação de Aperfeiçoamento de Pessoal de Nível Superior (Capes). Programa de Residência Pedagógica: resultado da terceira etapa de seleção - projeto institucional. 2018b Disponível em: http://200.130.18.222/images/stories/download/editais/resultados/01082018_Resultado_0744166_ RESULTADO_TERCEIRA_ETAPA__PAGINA_DA_CAPES.pdf. Acesso em: 28 out. 2018. 
BARDIN, Laurence. Análise de conteúdo. São Paulo: Edições 70, 2011.

FREIRE, Paulo. Pedagogia da autonomia: Saberes necessários à prática educativa. $7^{a}$ ed. São Paulo: Paz e Terra, 1996.

LÜDKE, Menga.; ANDRÉ, Marli. Pesquisa em Educação: abordagens qualitativas. São Paulo: Editora Pedagógica e Universitária, 1986.

MARCELO, Carlos. A identidade docente: constantes e desafios. Formação Docente. Belo Horizonte, v. 01, n. 01, p. 109-131, ago./dez. 2009. Disponível em http://formacaodocente.autenticaeditora.com.b. Tradução: Cristina Antunes.

NÓVOA, António O lugar da licenciatura. 2016. Disponível em: forproll.com/o-lugar-da-licenciatura/. Acesso em: 03 mar. 2019.

NÓVOA, António. Firmar a posição como professor, afirmar a profissão docente. Cadernos de Pesquisa. v. 47, n. 166, p. 1106-1136, out./dez. 2017.

NÓVOA, Antonio (Org.). Profissão professor. 2 ed. Porto: Porto Editora, 1999.

NÓVOA, Antonio (Org). Vida de professores. Porto: Porto Editora, 1992.

PIMENTA, Selma Garrido. Formação de professores: identidade e saberes da docência. In.: PIMENTA, Selma Garrido (Org.) Saberes pedagógicos e atividade docente. São Paulo: Cortez, 1999.

ROLDÃO, Maria do Céu. Função Docente: natureza e construção do conhecimento profissional. Revista Brasileira de Educação. v. 12, n. 34, jan./abr. 2007.

TARDIF, M.; LESSARD, C. O trabalho docente:elementos para uma teoria da docência como profissão de interações humanas. Petrópolis: Vozes, 2005.

TARDIF, M.; LESSARD, C.; LAHAYE, L. Esboço de uma problemática do saber docente. Teoria \& Educação. v. 1, n. 4, p. Teoria \& Educação 215-253, 1991.

TARDIF, Maurice. Saberes docentes e formação profissional. Petrópolis, R.J.: Editora Vozes, 2002.

TARDIF, Maurice; LESSARD, Claude; LAHAYE, Louise. Os professores face ao saber: esboço de uma problemática do saber docente. Teoria e Educação, n.4. Porto Alegre, RS. 1991.

TARDIF, Maurice; RAYMOND, Danielle. Saberes, tempo e aprendizagem do trabalho no magistério. Educação \& Sociedade, ano XXI, n 209 o 73, Dezembro/2000

UNIVERSIDADE FEDERAL DO PARÁ. Projeto Institucional: Residência Pedagógica. Belém, 2019. Impresso. 
ZEICHNER, Kenneth. Repensando as conexões entre a formação na universidade e as experiências de campo na formação de professores em faculdades e universidades. Educação, Santa Maria, v. 35, n. 3, p. 479-504, set./dez. 2010. Disponível em http://formacaodocente.autenticaeditora.com.br. Acesso em: 05 set. 2020.

ZEICHNER, Kenneth. A formação reflexiva de professores: ideias e práticas. Lisboa: Educa, 1993. 